\title{
Postradical cystectomy bowel perforation caused by a drainage
} tube: a case report

\author{
Eleftherios P Chatzidarellis*, Andreas Skolarikos, Evangelos Mazaris, \\ Iraklis Mitsogiannis and Gerasimos Alivizatos
}

Address: 2nd Department of Urology Athens Medical School, Sismanoglio Hospital, Athens, Greece

Email: Eleftherios P Chatzidarellis* - ehatzid@yahoo.gr; Andreas Skolarikos - andskol@yahoo.com; Evangelos Mazaris - evmazaris@yahoo.gr; Iraklis Mitsogiannis - icm@med.uth.gr; Gerasimos Alivizatos - gali@hol.gr

* Corresponding author

Published: 25 November 2008

Cases Journal 2008, 1:350 doi:10.1 186/1757-1626-1-350

This article is available from: http://www.casesjournal.com/content/I/I/350

(c) 2008 Chatzidarellis et al; licensee BioMed Central Ltd.

This is an Open Access article distributed under the terms of the Creative Commons Attribution License (http://creativecommons.org/licenses/by/2.0), which permits unrestricted use, distribution, and reproduction in any medium, provided the original work is properly cited.
Received: 28 May 2008

Accepted: 25 November 2008

\begin{abstract}
Introduction: Open drains are frequently placed in the abdominal cavity to prevent the collection of fluid or blood following major surgery.

Case presentation: We describe a case of perforation of the large bowel caused by the drain tube placed in a 74-year-old patient who had undergone radical cystectomy for invasive bladder cancer.
\end{abstract}

\section{Introduction}

Perforation of the large bowel secondary to pressure necrosis caused by open drainage tubes is an extremely rare complication following major intra-abdominal surgery. Currently only twelve cases been reported in the literature, all in general surgery operations [1-7]. We describe a similar case in a patient who underwent radical cystectomy for muscle-invasive bladder cancer. We also discuss possible predisposing and precipitating factors.

\section{Case presentation}

A 74-year-old patient with a past medical history of diabetes, cerebral vascular disease and a moderate degree of cardiac insufficiency underwent radical cystectomy for an extensive T2G3N0M0 bladder tumor. Prior to surgery there was no evidence of preexisting bowel disease, while the patient had never been operated intraabdominally or undergone a preoperative colonoscopy. A left crossed renal ectopia was found, during the urologic evaluation which included an excretory urogram (IVU) and an abdominal computed tomography scan.
The patient was classified as ASA score III and his operation was considered of increased surgical difficulty because of the presence of the fused left renal ectopia abutting the bladder and iliac vessels. As a consequence a fully informed consent was signed preoperatively. The patient underwent an uneventful 4-hour radical cystectomy and an ileal conduit with bilateral end to side uretero-enteric anastomoses was created. The stoma was fashioned at the pre-selected site at the right lower abdominal quadrant.

The peritoneal cavity was drained by an open-ended latex flexible tube of $8 \mathrm{~mm}$ in internal diameter which entered from the left lower quadrant and was placed at the pelvis, at a length of about $15 \mathrm{~cm}$. The tube was draining to gravity, without any suction. The drain had also two side holes at its last $5 \mathrm{~cm}$ length, for better drainage. Patients' recovery was slow, as bowel mobilization was delayed but without clinical or radiographical confirmed ileus. As a consequence the drain remained in the aforementioned position, although its output did not exceed $200 \mathrm{ml}$ for 
five days and there was no evidence of urine leakage. On the $6^{\text {th }}$ postoperative day, bowel content appeared in the drain. A contrast CT scan of the abdomen and pelvis revealed a patent and intact small bowel anastomosis but confirmed a sigmoid colon perforation. Recall of the surgical procedure and review of the CT films (Fig. 1, 2) indicated that the most likely cause of the perforation was "pressure necrosis" of the large bowel wall, secondary to the drainage tube apposition. The patient was treated conservatively with parenteral nutrition, intravenous antibiotics and repositioning of the tube away from the colon confirmed by a new CT scan. The initial decision for conservative management was based on the high mortality rate of re-operated patients described after radical cystectomy and due to absence of peritonitis. However, a laparotomy was performed on the $9^{\text {th }}$ postoperative day due to increased bowel content effluence and septicemia. The sigmoid colon perforation was confirmed, by finding a hole of about $5 \mathrm{~cm}$ in length and $1 \mathrm{~cm}$ in width and a Hartman's colectomy was performed. Although the drain had been withdrawn prior to the exploratory laparotomy, the shape of the bowel injury was consistent with an imprint of the drain, as shown in the CT scan preoperatively.(Fig 1) Patient's recovery was further complicated by an ischemic acalculous cholecystitis necessitating a cholecystectomy on postoperative day 14 . On the $26^{\text {th }}$ postoperative day and due to ongoing and refractory sepsis the patient deceased. Histopathology of the resected left colon revealed ischaemic bowel disease with extensive bowel mucosa necrosis and atherosclerotic plaques and thrombotic lesions of the bowel wall vessels.

\section{Discussion}

Bowel perforation caused by drainage tubes following abdominal surgery is a rare complication, with only

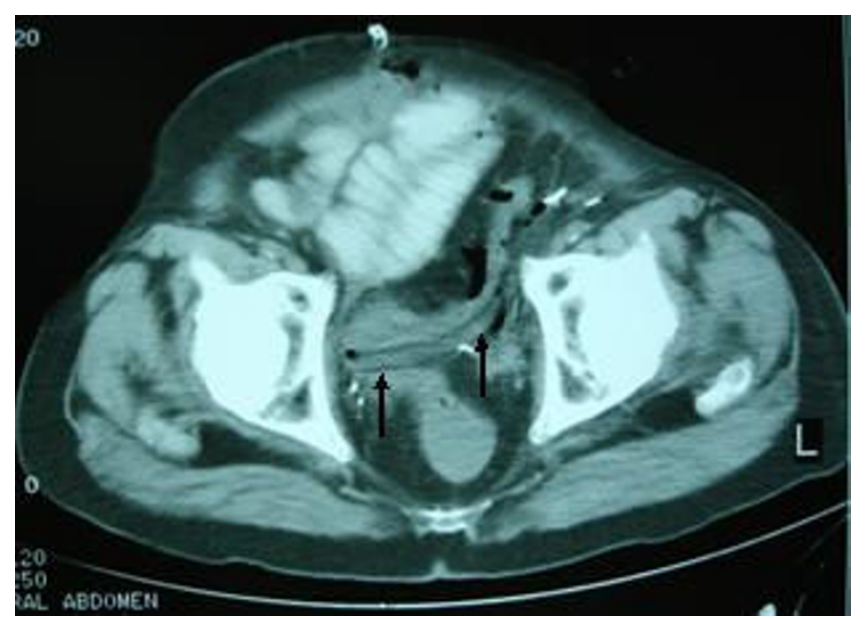

Figure I

CT scan at case presentation. Computed tomography showing the drain abutting the sigmoid colon.

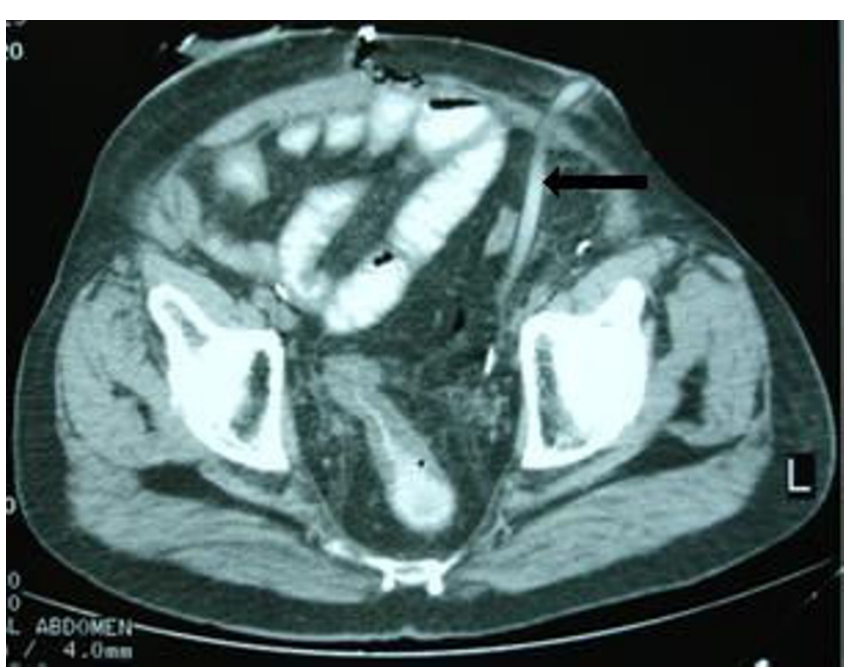

Figure 2

CT scan at case presentation. Computed tomography demonstrates gastrografin into the drain.

twelve cases thus far reported in literature [1-7]. All cases occurred in general surgical procedures, while this rare complication has never been reported following Urological surgery. The underlying mechanism responsible for this complication differs depending on the type of the drains used. Bowel wall can be drawn into the side holes of a suction drain due to the creation of high negative pressure which can reach the level of $-180 \mathrm{mmHg}$ [8]. Open drains may cause perforation due to pressure necrosis by the tip of the tube. In addition, "stripping" of silicon surgical drains may increase the negative pressure to a level of $-80 \mathrm{mmHg}$.[8] We retrospectively tried to identify predisposing or precipitating factors for this complication. Radical cystectomy in patients with fused pelvic "lump" kidneys has rarely been reported [9-11]. Three previous reports indicated a higher difficulty compared to formal cystectomies, mainly due to the alternate vascularization and to the shortness of the left ureter. However, in our case there was no difficulty in identifying the left ureter, while its length was adequate for re-implantation. The possibility of an iatrogenic injury of the bowel with the use of cautery, cannot be excluded but is considered highly unlikely, since ligation of vessels close to the bowel was only performed by sutures. Dissecting the sigmoid colon away was easy without any obvious serosal tears or injury of its arterial supply. Ischemic arterial disease was the main predisposing factor in our case as was indicated by the patient's medical history and according to the pathology report. The complication was precipitated by the late withdrawal of the drainage tube. This was mainly due to the delayed bowel function restoration in our patient. In order to avoid this complication, soft-type drains should be placed carefully without suction and 
removed or mobilized early after the drain fluid has decreased, especially when patients with vascular insufficiency are being operated on.

\section{Abbreviations}

ASA: American Society of Anesthesiologists; CT: Computed Tomography.

\section{Consent}

Written informed consent was obtained from the patient's sons for publication of this case report and any accompanying images. A copy of the written consent is available for review by the Editor-in-Chief of this journal.

\section{Competing interests}

The authors declare that they have no competing interests.

\section{Authors' contributions}

EPC, AS, EM, IM and GA conceived the study and participated in its design, coordination and helped to draft the manuscript. All authors read and approved the final manuscript.

\section{Acknowledgements}

The authors gratefully acknowledge the advice and assistance of Konstantinos Delamarinis, MD (Radiologist)

\section{References}

I. Hee RV: Complication of drainage. Acta Chir Belg 1983, 83:340-344.

2. Benjamin PJ: Faeculent peritonitis: a complication of vacuum drainage. Br J Surg 1980, 67:453-454.

3. Gray AJ, Copeland GP: Small bowel perforation following vacuum suction drainage. I $R$ Coll Surg Edinb 1985, 30:324-325.

4. Reed MW, Wyaman A, Thomas WE, Zeiderman MR: Perforation of the bowel by suction drains. BrJ Surg 1992, 79:679.

5. Grunewald B, Kato G: Intestinal perforation by suction drains. N Z Med J 1997, I I 0(1 036):19.

6. Nomura T, Shirai $Y$, Okamoto H, Hatakeyama K: Bowel perforation caused by silicone drains: A report of two cases. Surg Today Jpn J Surg 1998, 28:940-942.

7. Wang JY, Hsieh JS, Chen FM, Lee LW, Hou MF, Huang YS, Huang TJ: Rectal perforation secondary to surgical drains after low anterior resection: a report of two cases and review of the literature. Kaohsiung / Med Sci 2002, I8(3): | 46-| 48.

8. Graham D, Coit D, Brennan MF: Perforation of the bowel by suction drains. Br J Surg 1993, 80:128-129.

9. Vaughn W, Hickey D, Milam HW, Soloway M: Radical Cystectomy in presence of fused "cake" kidney. Urology 1987, 29:552-554.

10. Quek ML, Basrawala Z, McClung C, Flanigan RC: Radical cystectomy with extended lymphadenectomy in the presence of a pelvic kidney. Urology 2006, 68:672.e2I-672.e22.

II. Iritiani Y, Yoshimoto M, Yamaguchi T, Maekawa M: A case of fused pelvic kidney (lump kidney) with invasive bladder tumor. Hinyokika Kiyo 1989, 35(6): 1041-1045.

\section{Publish with Biomed Central and every} scientist can read your work free of charge

"BioMed Central will be the most significant development for disseminating the results of biomedical research in our lifetime. "

Sir Paul Nurse, Cancer Research UK

Your research papers will be:

- available free of charge to the entire biomedical community

- peer reviewed and published immediately upon acceptance

- cited in PubMed and archived on PubMed Central

- yours - you keep the copyright 